\title{
A national survey of Canadian emergency medicine residents' comfort with geriatric emergency medicine
}

\author{
Tristan Snider, $\mathrm{MD}^{*}$; Don Melady, $\mathrm{MD}^{\dagger \neq}$; Andrew P. Costa, $\mathrm{PhD}^{\S}$
}

\section{ABSTRACT}

Background: Geriatric patients represent a large and complex subgroup seen in emergency departments (EDs). Competencies in geriatric emergency medicine (EM) training have been established. Our objectives were to examine Canadian postgraduate year (PGY)-5 EM residents' comfort with the geriatric EM competency domains, assess whether Canadian EM residents become more comfortable through residency, and determine whether geriatric educational exposures are correlated with resident comfort with geriatric EM.

Methods: A national, cross-sectional study of PGY-1 and PGY-5 Royal College EM residents was conducted to determine their comfort in geriatric EM clinical competency domains. Residents reported their level of comfort in satisfying each competency domain using a seven-point Likert scale. Residents were also asked about the location of their medical education as well as the type and number of different geriatric exposures that they had received to date.

Results: Of the 141 eligible residents from across Canada, $77 \%$ (109) consented to participate. None of the PGY-1 EM residents and $34 \%$ (14) of PGY-5 EM residents reported that they were comfortable with all eight geriatric EM competency domains. PGY-5 EM residents were significantly more comfortable than PGY-1 EM residents. Residents reported a highly variable range of geriatric educational exposures obtained during training. No relationship was found between resident-reported comfort and the nature or number of geriatric exposures that they had received.

Conclusion: Current Royal College EM residency training in Canada may not be adequately preparing graduates to be comfortable with defined competencies for the care of older ED patients.

\section{RÉSUMÉ}

Introduction: Les personnes âgées forment un sous-groupe important et très diversifié de patients au service des urgences (SU). Les compétences à acquérir durant la formation en médecine d'urgence (MU) gériatrique sont déjà établies. L'étude visait à examiner l'aisance des résidents en formation postdoctorale de niveau V ("PGY-5 ") en MU au Canada dans les domaines de compétences en MU gériatrique; à évaluer si l'aisance des résidents en $\mathrm{MU}$ au Canada s'améliorait au fil de la formation; et à déterminer s'il y avait une corrélation entre l'aisance des résidents en MU gériatrique et l'exposition à différents cas de gériatrie durant la formation.

Méthode: Une étude transversale a été menée à l'échelle nationale parmi les résidents en formation postdoctorale des niveaux $\mathrm{I}$ et $\mathrm{V}$ en $\mathrm{MU}$ du Collège royal des médecins et chirurgiens du Canada afin de déterminer leur aisance dans les domaines de compétences cliniques en MU gériatrique. Les résidents ont exprimé leur degré d'aisance dans chacun des domaines de compétences à l'aide d'une échelle de Likert en 7 points. Les résidents devaient également indiquer le lieu de leur formation médicale ainsi que le type et le nombre de cas en gériatrie auxquels ils avaient été exposés jusqu'au moment de l'enquête.

Résultats: Sur 141 résidents admissibles à l'étude partout au Canada, 77\% (109) ont accepté d'y participer. Aucun des résidents de niveau I ne s'est déclaré à l'aise dans les huit domaines de compétences en MU gériatrique, tandis que $34 \%$ (14) des résidents de niveau $V$ ont indiqué l'être. Les résidents de niveau $\mathrm{V}$ en $\mathrm{MU}$ se sentaient beaucoup plus à l'aise que les résidents de niveau I. Les résidents ont fait état d'une exposition à une grande diversité de cas en gériatrie durant leur formation en spécialité. Aucune relation n'a été établie entre l'aisance déclarée des résidents et la nature ou le nombre de cas qu'ils avaient vus en gériatrie.

Conclusion: La formation actuelle en MU du Collège royal au Canada peut ne pas rendre les résidents suffisamment à l'aise dans les domaines de compétences à acquérir en matière de soins aux personnes âgées au SU.

Keywords: competence, education, emergency medicine, geriatrics, postgraduate, resident

From the *The Royal College Emergency Medicine Residency Program, Division of Emergency Medicine, Department of Medicine, University of Toronto, Toronto, ON; †Schwartz/Reisman Emergency Centre, Mount Sinai Hospital, Toronto, ON; $\neq$ Department of Family and Community Medicine, University of Toronto, Toronto, ON; and §Department of Clinical Epidemiology and Biostatistics and Department of Medicine, McMaster University, Hamilton, ON.

Correspondence to: Dr. Tristan Snider, Division of Emergency Medicine, Sunnybrook Health Sciences Centre, 2075 Bayview Ave, C7-53, Toronto, ON M4N 3M5; Email: Tristan.snider@mail.utoronto.ca 


\section{INTRODUCTION}

There has been a steady increase in emergency department (ED) visits and resource use by adults over 65 years of age. ${ }^{1}$ About $20 \%$ of current ED patients are geriatric, and that proportion is expected to increase substantially. ${ }^{2}$ In fact, the geriatric demographic is the only age cohort with increasing ED visit rates in Canada. ${ }^{3}$ Most clinicians indicate that older patients are among the most complex, time- and resource-intensive of all ED patients. ${ }^{4-6}$

In an environment that increasingly incentivizes flow and rapid management, emergency physicians (EPs) are required to rapidly assess older patients who can have atypical presentations of disease, cognitive impairment or multiple other chronic conditions, be on multiple medications, and have either inadequate social supports or multiple community-care providers. $^{4-7}$ Older patients are more likely to experience adverse events in the $\mathrm{ED}^{8}{ }^{8}$ including iatrogenic injury, ${ }^{9}$ missed diagnoses, ${ }^{10}$ omitted treatments, ${ }^{11-13}$ poor medical outcomes, ${ }^{14,15}$ death,${ }^{16}$ functional decline, ${ }^{17-19}$ prolonged stays, ${ }^{16}$ necessity for a discharge to a higher level of care, ${ }^{20}$ and repeat ED use. ${ }^{21,22}$ A 1992 American study reported that EPs found it challenging to provide consistently high-quality care for older patients. ${ }^{23}$ Improving the balance between rapid flow and optimal outcomes in the geriatric population may require both readjustment of the model of care for older adults ${ }^{7}$ and disruptive innovation-beginning with geriatric emergency medicine education. ${ }^{24}$

It is expected that EPs develop the ability to care for older patients during undergraduate medical education (UGME) and postgraduate medical education (PGME). However, evidence suggests that current EM training relating to the care of the elderly may not provide adequate preparation for the "Silver Boom" about to hit our EDs. ${ }^{23,25}$ This training gap has been recognized in the United States, where both the Institute of Medicine ${ }^{26}$ and the American College of Emergency Physicians ${ }^{27}$ have called for improved geriatric EM training.

In 2011, Biese et al. found that geriatric educational curricula for EM residents may positively affect knowledge base and appropriate decision-making, and may place elderly patients at less risk of adverse outcomes in the ED. ${ }^{28}$ In 2010, Hogan et al. established a set of eight core geriatric EM competency domains using a consensus-based approach. ${ }^{29}$ These represent a minimum set of behaviourally based performance standards that arguably all EM residents should be able to demonstrate by completion of their residency training.

Our primary objective was to determine whether graduating Canadian postgraduate year (PGY)-5 residents are comfortable with the above-mentioned geriatric EM competency domains. Our secondary objectives were to assess whether Canadian EM residents become more comfortable through the course of their residency, and whether a relationship exists between geriatric educational exposures and resident comfort with geriatric EM. We hypothesized that the majority of graduating Canadian EM residents would not report being comfortable with all of the core geriatric EM competency domains.

\section{METHODS}

\section{Study design}

This was a national cross-sectional study of Canadian Royal College EM PGY-1 and PGY-5 residents. We evaluated resident self-reported comfort with the eight previously reported geriatric EM competency domains (Figure 1). In order to limit non-response, coverage, sampling, and measurement error, we used Dillman's tailored design method guidelines ${ }^{30}$ to develop an eight-question online survey tool (Appendix 1). We pilot tested the survey on five PGY-3 residents and two medical students to ensure clarity, face validity, and content validity. We deemed that a peer-reviewed pre-study of the internal and external validity and reproducibility of our survey tool was unnecessary, owing to our adherence to established survey creation guidelines, ${ }^{30}$ internal pilot testing, and ease of access to, and high expected response rate from, our study population. We incentivized participation with a $\$ 10$ gift certificate provided to residents who completed the survey through an anonymous link. The study was approved by the Mount Sinai Hospital Research Ethics Board in Toronto, Ontario.

\section{Study settings and participants}

An anonymous survey was distributed in June 2014 to the program directors of the 14 Canadian Royal College EM residency training programs who then forwarded it to the incoming PGY-1 cohort (in July) and the graduating PGY-5 cohort (in June). This timing allowed 
1. Atypical presentation of disease

- An appreciation of falls, weakness, confusion, and "dizziness" as symptoms of serious emergent conditions and adverse drug events.

2. Trauma, including falls

- An ability to comprehensively assess an older person who has fallen - etiology, injuries, safety, prevention - and to appropriately alter the approach to trauma resuscitation.

3. Cognitive and behavioral disorders

- An awareness of dementia as complicating factor for acquiring a history and interacting with the patient; an ability to thoroughly and efficiently assess the etiology of delirium; and an appreciation of multi-factorial management of agitation.

4. Emergent intervention modifications

- An ability to appropriately modify "standard" approaches to care that address the specific risks and benefits for the older person; and an attention to protecting older patients from iatrogenic harm.

5. Medication management

- An awareness of aging physiology and its effect on medication for the patient's acute and chronic conditions; and of high-risk medication classes.

6. Transitions of care

- An ability to effectively gather and transmit information from and to others (primary care, long-term care, specialists, home care) involved in the continuum of care; and to arrange for the most suitable discharge plan from the ED.

7. Pain management and palliative care

- An ability to quickly establish goals of care and to develop an ED plan consistent with them; a facility with advanced management of pain and non-pain symptoms.

8. Effect of comorbid conditions

- An ability to manage patients with inter-related active problems in multiple organ systems as well as cognitive, sensory, functional impairments; and inadequate social supports.

Figure 1. Geriatric competency domains for EM residents. ${ }^{29}$

access to incoming residents in the first month of their postgraduate training and outgoing residents in their last month. All Canadian PGY-1 residents and PGY-5 residents were eligible to participate. The potential sample included 141 residents from across Canada: 77 PGY-1 residents ${ }^{31}$ and 64 PGY-5 residents. ${ }^{32}$ 


\section{Variables}

Each survey question contained a completely described, common geriatric ED scenario linked to one of the eight domains of geriatric EM competence followed by the specific core competencies associated with that domain. The questions were closed-ended with naturally ordered responses. The survey asked residents to rank their comfort level in providing competent care with respect to each scenario on a seven-point Likert scale. The scale options were "Very Uncomfortable," "Uncomfortable," "Somewhat Uncomfortable," "Neither Comfortable nor Uncomfortable," "Somewhat Comfortable," "Comfortable," or "Very Comfortable."

We also assessed the types of geriatric education that the residents experienced during training (UGME or PGME). The types of geriatric EM training exposures are described in Appendix 2. Our primary outcome was the proportion of "comfort" for each geriatric EM competency domain, and we established, a priori, that "comfort" in any domain would be attributed to "Comfortable" or "Very Comfortable" responses. Our secondary outcome was the number of geriatric EM competency domains scored as "Comfortable" or "Very Comfortable." Independent variables captured included the PGY as well as the type and number of different geriatric EM exposures per PGY. We did not collect data on standard demographics to maintain the anonymity of participants from smaller residency programs.

\section{Data analysis}

Stratified analyses were used to investigate the prevalence of self-reported comfort in geriatric EM competencies by PGY. Ninety-five percent confidence intervals for prevalence statistics were based on the binomial estimation of the standard error of a proportion. Because this was a population level survey, these confidence limits mainly show the presumed representativeness of the proportions across resident EM cohorts. The chi-square test was used to examine the relationship between comfort in geriatric EM competency domains and the variation in geriatric educational exposures, and $p$ less than or equal to 0.05 was considered statistically significant. All analyses were performed using SAS version 9.2 for Windows (SAS Institute, Inc., Cary, NC). The results of this study were reported according to the STROBE statement. ${ }^{33}$

\section{RESULTS}

Of the 141 eligible residents from across Canada, $77 \%$ (109) participated: $88 \%$ (68) of PGY-1 residents and $64 \%$ (41) of PGY-5 residents. All Canadian EM residency training programs were represented in the responses. The response rate for individual programs ranged from $20 \%$ to $94 \%$.

The proportion of residents who reported being comfortable with each competency domain by PGY is shown in Figure 2. Among PGY-5 residents, between $68 \%$ and $88 \%(28-36)$ reported being comfortable in

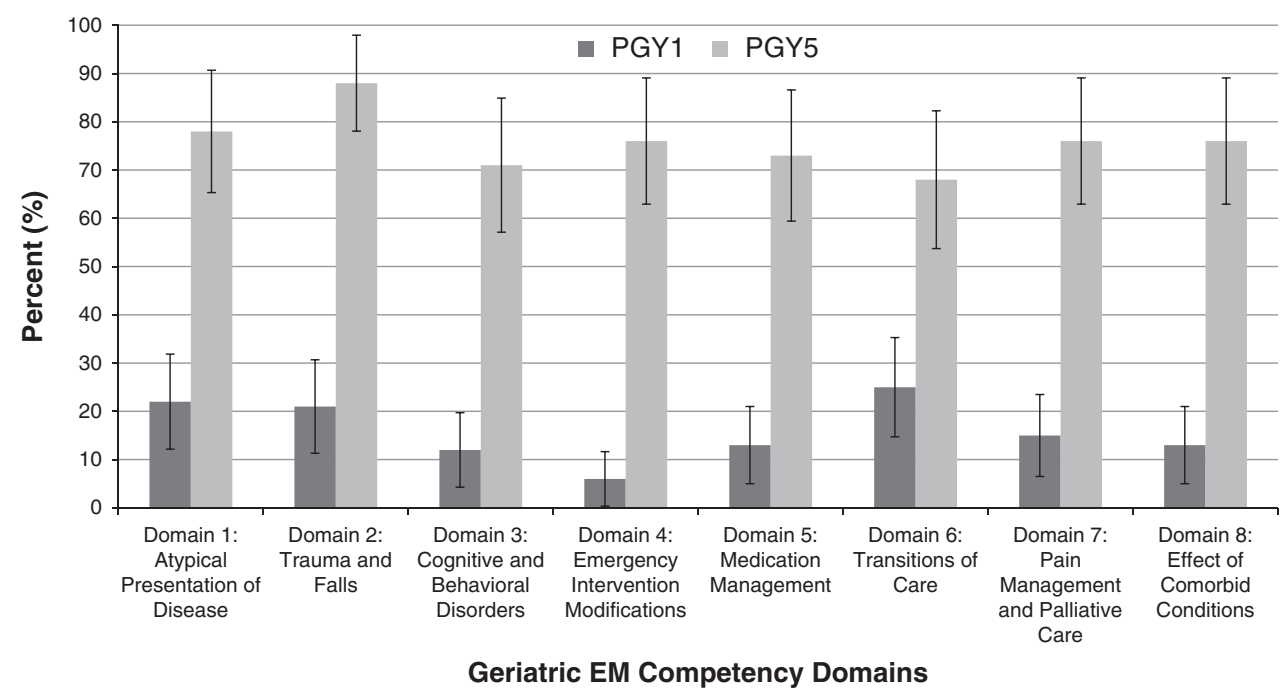

Figure 2. Proportion of residents reporting comfort for each geriatric EM competency domain, by postgraduate year. 




Figure 3. Number of competencies that residents reported being comfortable with, by postgraduate year.

each geriatric EM competency domain. Although variation was seen, no statistically significant difference was found in PGY-5 comfort between the eight geriatric EM competency domains. Among PGY-1 residents, between $6 \%$ and $25 \%(4-19)$ reported being comfortable in each domain. With the exception of the domain of "Emergency Intervention Modifications," no significant difference was found in PGY-1 comfort between the geriatric EM competency domains. PGY-5 EM residents were found to be significantly more comfortable relative to PGY-1 residents across all eight geriatric EM competency domains $(p<0.05)$.

Figure 3 illustrates the number of competencies in which PGY-1 and PGY-5 residents reported being comfortable. We found that $34 \%$ (14) of PGY-5 residents and $0 \%$ of PGY-1 residents reported comfort with all eight domains $(p<0.05)$. Fifty percent of PGY-1 residents and 2\% of PGY-5 residents reported being "Very Uncomfortable" with all eight domains $(p<0.05)$.

Figure 4 illustrates the types of geriatric-specific educational exposures reported. Residents reported a highly variable range of geriatric educational exposures obtained during training. On average, PGY-5 residents reported experiencing seven different geriatric EM exposures during PGME (with a range of one and twelve exposures). The majority ( $>50 \%)$ of PGY -5 residents had some geriatric-specific educational exposure through clinical teaching, lectures, rounds, oral exams, directed readings, and journal clubs. Less than $20 \%$ of PGY-5 residents reported that they had exposure to geriatric-specific rotations, courses, research, premed training, problem-based learning, and assignments during PGME. On average, PGY-1 residents had experienced six different geriatric EM exposures during UGME (with a range of 1 and 10 exposures). The majority of PGY-1 residents reported that they had some exposure to clinical teaching, lectures, problem-based learning, rounds, and directed learning related to geriatrics. We found no relationship between resident comfort with geriatric EM competency domains and the nature or number of geriatric educational exposures that the residents had previously received.

\section{DISCUSSION}

To our knowledge, this is the first study to investigate EM residents' comfort with geriatric ED care both at the beginning and end of their training, and the educational experiences that they receive in this area.

Our findings suggest that comfort level with the core domains of caring for older ED patients does increase dramatically throughout the 5 years of residency training. However, we also found that in the month immediately before completing their training, only 34\% of Canadian EM residents report feeling comfortable in all domains of geriatric EM, and, for any given domain only, $68 \%-88 \%$ of residents felt comfortable. These findings can be interpreted from either a "glass half full" or "glass half empty" perspective. However, we doubt that it would be considered acceptable if only one-third of graduating EM 


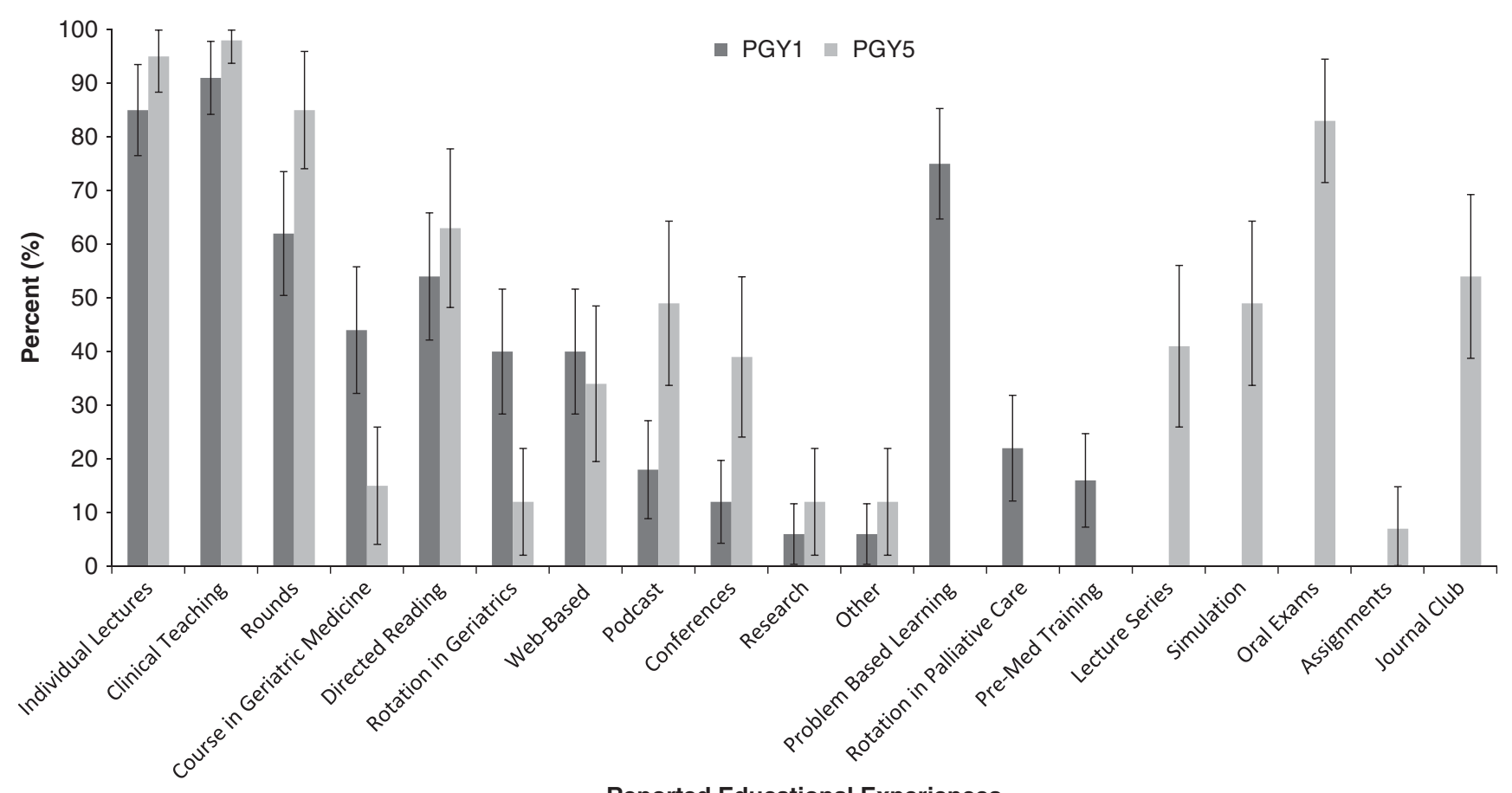

Reported Educational Experiences

Figure 4. Reported geriatric educational exposures, by postgraduate year.

residents reported feeling comfortable with, for example, the core competency domains of pediatrics, trauma, or resuscitation. Our findings suggest that current Royal College EM residency training in Canada may not adequately be preparing graduates to be comfortable with defined competencies for the care of older ED patients, and by extension may not adequately be preparing future EPs to provide care to the geriatric EM population. It is conceivable that this finding may be generalizable both to other specialties and to other countries regarding their preparation of future physicians for upcoming demographic shifts in EM presentations.

Fifty percent of residents in their first month of postgraduate training said that they are not comfortable with any geriatric EM competency domains. We acknowledge that early residency is a period marked by perceived inadequacy and uncertainty about competence. Nonetheless, we would be surprised if the same lack of comfort were expressed about other areas of standard EM care, including trauma, resuscitation, procedural skills, and critical illness.

We found that medical students and residents are exposed to a variable range of geriatric EM experiences. We also found no relationship between the nature or number of different educational exposures that residents reported and their reported comfort with the core geriatric competencies. This lack of correlation may be explained by inadequacies of our surveying technique or by inadequacies in the educational content of experiences that may do little to change skills, knowledge, or attitudes with regards to geriatric EM. Currently, there is no standard geriatric EM training across Canada, and thus the skills that a new EP has with respect to geriatric EM will vary. Section 2.3 of the Royal College of Physicians and Surgeons of Canada, "Objectives of Training in Emergency Medicine," specifically notes that geriatric EM care is an area in which residents must be competent. ${ }^{34}$ However, despite the high proportion of complex geriatric patients in EDs, the Royal College "Minimum Training Requirements for Specialty Training in Emergency Medicine" do not stipulate a specific rotation in geriatrics, whereas, in contrast, they do require a minimum of 4 months with a pediatric clinical emphasis. ${ }^{35}$ Given the lack of requirement for a specific rotation in geriatrics, it is perhaps not surprising that less than $20 \%$ of PGY-5 residents reported undertaking a rotation in geriatrics.

Because numerous studies have demonstrated deficiencies in ED care for older adults ${ }^{36,37}$ with falls, ${ }^{38}$ dementia, ${ }^{39,40}$ or delirium, ${ }^{40}$ a concern exists that 
EPs-whose training is focused on the time-dependent skills in areas such as trauma, resuscitation, procedures, and critical illness-may be inadequately prepared to manage the complexity associated with providing care for the geriatric population. The management of frail elderly patients with atypical presentations, polypharmacy, and polymorbidity who are navigating transitions through a complex health care system, is often at odds with the classic "single patient/single problem" paradigm of EM training. It stands to reason that the implementation of a standard geriatric EM curriculum or addition of curricular expectations across all Canadian EM programs may produce a cohort of EPs that is more consistently comfortable with care of elderly patients. Strategies may include focused geriatric EM rotations, online modules, or supplementary rotations in relevant fields such as palliative medicine, acute geriatric medicine, and communitybased geriatric clinics. Our results show that such educational strategies are rarely employed in Canada. As EM moves towards a competency-based education model, it will be important to identify competent care of the older ED patient as an "entrustable professional activity" with clear milestones and benchmarks identified for EM residents progressing through residency. ${ }^{41}$

We acknowledge that it is difficult for PGME programs to find time and resources to expand resident curricula, and there are many topics to cover for a generalist specialty such as EM. The introduction of a self-directed online competency-based approach may address the problem of limited time and resources. This method is already in place at one Canadian postgraduate site, using a flipped classroom approach through the website, www.geri-em.com.

\section{LIMITATIONS}

The ideal study design to assess resident ability to care for older adults would be direct observation and assessment of resident competence in caring for older patients. In the absence of that ideal, we assessed a possible surrogate for competence, that is, residents self-reported level of comfort with each of the eight competency domains of geriatric EM. We chose this approach as a first step knowing that, while the education literature suggests that self-assessment of competence is unreliable, self-assessment of comfort is intrinsically accurate. ${ }^{42,43} \mathrm{We}$ posited that there is a connection between self-perceived comfort with an activity and actual competence with that activity. The survey tool used in the study was original and was designed for our specific purpose and thus lacks criterion validity (there are no current measures of resident comfort or ability to test our survey against). Our survey did not provide information about the quality of educational exposures, only the number and nature of different exposures. As a result, a 1-hour lecture in medical school and a full clinical rotation in residency would both count as one experience. This study was limited to the Royal College EM residency program and did not include the EM residents in the College of Family Physicians of Canada CCFP(EM) program. Finally, the demographic characteristics of neither the sample population nor the nonparticipants were collected and the survey was available in English only.

\section{CONCLUSIONS}

Our data show that one-third of graduating Canadian Royal College EM residents are comfortable with all core competency domains of care of older persons in the ED. Canadian EM residents are exposed to a variable range of geriatric EM exposures across. However, current EM residency training in Canada may not be preparing practitioners adequately to provide competent care for older patients. The addition of focused geriatric EM content may improve resident comfort with geriatric EM competencies.

\section{SUPPLEMENTARY MATERIAL}

To view supplementary material for this article, please visit http://dx.doi.org/10.1017/cem.2016.27

Acknowledgements: The authors gratefully acknowledge the generous support of their clinical and research emergency department colleagues who made this study possible. TS and DM led recruitment in consultation with all of the listed authors. APC led the analysis in consultation with all of the listed authors. TS led the manuscript. All authors contributed to the final manuscript and approved its content.

Competing interests: Funding sources and disclosures Support for this project was provided by the Penny Rubinoff Fellowship Fund in Geriatric Emergency Medicine and the Schwartz/Reisman Emergency Medicine Institute. The opinions and conclusions expressed in this article are those of the authors and do not necessarily reflect the views of the contributing centers or funders. 


\section{REFERENCES}

1. Pines JM, Mullins PM, Cooper JK, et al. National trends in emergency department use, care patterns, and quality of care of older adults in the United States. 7 Am Geriatr Soc 2013;61(1):12-7.

2. Woford JL, Schwartz E, Timerding BL, et al. Emergency department utilization by the elderly: analysis of the National Hospital Ambulatory Medical Care Survey. Acad Emerg Med 1996;3(7):694-9.

3. Benjamin CTB, Schull MJ, Schultz SE. Emergency Department Services in Ontario 1993-2000. Institute for Clinical Evaluative Sciences; 2001. Available at: http://www. ices.on.ca/ /media/Files/Atlases-Reports/2001/Emergencydepartment-services-in-Ontario/Full\%20Report.ashx (accessed July 11, 2015).

4. Strange GR, Chen EH. Use of emergency departments by elder patients: a five-year follow-up study. Acad Emerg Med 1998;5(12):1157-62.

5. Costa AP, Hirdes JP, Heckman GA, et al. Geriatric syndromes predict postdischarge outcomes among older emergency department patients: findings from the interRAI Multinational Emergency Department Study. Acad Emerg Med 2014;21(4):422-33.

6. Gray LC, Peel NM, Costa AP, et al. Profiles of older patients in the emergency department: findings from the interRAI Multinational Emergency Department Study. Ann Emerg Med 2013;62(5):467-74.

7. Carpenter CR, Platts-Mills TF. Evolving prehospital, emergency department, and "inpatient" management models for geriatric emergencies. Clin Geriatr Med 2013; 29(1):31-47.

8. Liu SW, Thomas SH, Gordon JA, et al. A pilot study examining undesirable events among emergency department-boarded patients awaiting inpatient beds. Ann Emerg Med 2009;54(3):381-5.

9. Fakih MG, Shemes SP, Pena ME, et al. Urinary catheters in the emergency department: very elderly women are at high risk for unnecessary utilization. Am $\mathcal{F}$ Infect Control 2010; 38(9):683-8.

10. Sanders AB, Morley JE. The older person and the emergency department. 7 Am Geriatr Soc 1993;41(8):880-2.

11. Krumholz HM, Radford MJ, Wang Y, et al. Early betablocker therapy for acute myocardial infarction in elderly patients. Ann Intern Med 1999;131(9):648-54.

12. Magid DJ, Masoudi FA, Vinson DR, et al. Older emergency department patients with acute myocardial infarction receive lower quality of care than younger patients. Ann Emerg Med 2005;46(1):14-21.

13. Rathore SS, Mehta RH, Wang Y, et al. Effects of age on the quality of care provided to older patients with acute myocardial infarction. Am $\mathcal{F}$ Med 2003;114(eta4): 307-15.

14. Denman SJ, Ettinger WH, Zarkin BA, et al. Shortterm outcomes of elderly patients discharged from an emergency department. $\mathcal{F}$ Am Geriatr Soc 1989;37(10): 937-43.

15. Friedmann PD, Jin L, Karrison TG, et al. Early revisit, hospitalization, or death among older persons discharged from the ED. Am 7 Emerg Med 2001;19(2):125-9.
16. McCusker J, Bellavance F, Cardin S, et al. Detection of older people at increased risk of adverse health outcomes after an emergency visit: the ISAR screening tool. $7 \mathrm{Am}$ Geriatr Soc 1999;47(10):1229-37.

17. Chin MH, Jin L, Karrison TG, et al. Older patients' healthrelated quality of life around an episode of emergency illness. Ann Emerg Med 1999;34(5):595-603.

18. Hastings SN, Heflin MT. A systematic review of interventions to improve outcomes for elders discharged from the emergency department. Acad Emerg Med 2005;12(10): 978-86.

19. McCusker J, Bellavance F, Cardin S, et al and Identification of Seniors at Risk Steering C: Screening for geriatric problems in the emergency department: reliability and validity. Acad Emerg Med 1998;5(9):883-93.

20. McCusker J, Bellavance F, Cardin S, et al. Prediction of hospital utilization among elderly patients during the 6 months after an emergency department visit. Ann Emerg Med 2000;36(5):438-45.

21. Caplan GA, Brown A, Croker WD, et al. Risk of admission within 4 weeks of discharge of elderly patients from the emergency department-the DEED study. Discharge of elderly from emergency department. Age Ageing 1998;27(6): 697-702.

22. McCusker J, Cardin S, Bellavance Fo, et al. Return to the emergency department among elders: patterns and predictors. Acad Emerg Med 2000;7(3):249-59.

23. McNamara RM, Rousseau E, Sanders AB. Geriatric emergency medicine: a survey of practicing emergency physicians. Ann Emerg Med 1992;21(7):796-801.

24. Hwang U, Shah MN, Han JH, et al. Transforming emergency care for older adults. Health Aff (Project Hope) 2013;32(12):2116-21.

25. Carpenter CR, Lewis LM, Caterino JM, et al 375. Emergency physician geriatric education: an update of the 1992 Geriatric Task Force Survey. Has anything changed? Ann Emerg Med 2008;52(4 Suppl):S156.

26. Committee on the Future Health Care Workforce for Older Americans, Institute of Medicine. The Professional Health Care Workforce. In Retooling for an aging America: building the bealth care workforce. Washington, DC: National Academies Press; 2008, 123-97.

27. Physicians ACoE. Report on the future of geriatric care in our nation's emergency departments: impact and implications. Irving: American College of Surgeons; 2008.

28. Biese KJ, Roberts E, LaMantia M, et al. Effect of a geriatric curriculum on emergency medicine resident attitudes, knowledge, and decision-making. Acad Emerg Med 2011; 18(Suppl 2):S92-6.

29. Hogan TM, Losman ED, Carpenter CR, et al. Development of geriatric competencies for emergency medicine residents using an expert consensus process. Acad Emerg Med 2010; 17(3):316-24.

30. Dillman DA, Christian LM, Smyth JD. Internet, mail, and mixed-mode surveys: the tailored design method. 3rd ed. Hoboken, NJ: Wiley \& Sons, 2009.

31. Canadian Resident Matching Service (CaRMS). Quota Overview by University, 2014 R-1 Match - Match - First Iteration, Discipline. Emergency medicine; 2014. Available at: https:// phx.e-carms.ca/phoenix-web/pd/main?mitid=1201. 
32. CAPER. Individual Field of Training Tables 2013-14. Available at: http://www.caper.ca/ assets/pdf_2013-14_ Individual_Specialty_Tables.pdf.

33. von Elm E, Altman DG, Egger M, et al. The strengthening the reporting of observational studies in epidemiology (STROBE) statement: guidelines for reporting observational studies. Int 7 Surg 2014;12(12):1495-9.

34. Royal College of Physicians and Surgeons of Canada. Objectives of training in the specialty of emergency medicine; 2014. Available at: http://www.royalcollege.ca/cs/ groups/public/documents/document/y2vk/mdaw/ edisp/ tztest3rcpsced000895.pdf.

35. Royal College of Physicians and Surgeons of Canada. Specialty training requirements in emergency medicine. Available at: http://www.royalcollege.ca/cs/idcplg?IdcService= GET_FILE\&dID=36401\&dDocName=TZTEST3RCPSC ED000617.

36. Aminzadeh F, Dalziel WB. Older adults in the emergency department: a systematic review of patterns of use, adverse outcomes, and effectiveness of interventions. Ann Emerg Med 2002;39(3):238-47.

37. Schnitker L, Martin-Khan M, Beattie E, et al. Negative health outcomes and adverse events in older people attending emergency departments: a systematic review. Australas Emerg Nurs 7 2011;14(3):141-62.

38. Tirrell G, Sri-on J, Lipsitz LA, et al. Evaluation of older adult patients with falls in the emergency department: discordance with national guidelines. Acad Emerg Med 2015; 22(4):461-7.

39. Schnitker LM, Martin-Khan M, Burkett E, et al. Appraisal of the quality of care of older adults with cognitive impairment in the emergency department. 7 Gerontol Nurs 2013; 39(3):34-40.

40. Schnitker LM, Martin-Khan M, Burkett E, et al. Process quality indicators targeting cognitive impairment to support quality of care for older people with cognitive impairment in emergency departments. Acad Emerg Med 2015;22(3): 285-98.

41. ten Cate O. Nuts and bolts of entrustable professional activities. 7 Grad Med Educ 2013;5(1):157-8.

42. Eva KW, Regehr G. "I'll never play professional football" and other fallacies of self-assessment. 7 Contin Educ Health Prof 2008;28(1):14-9.

43. Brian D, Hodges LL. The question of competence: reconsidering medical education in the twenty-first century. Ithaca: Cornell University Press, ILR Press; 2012. 